\title{
Combining regenerated gratings and optical fibre Fabry-Pérot cavities for dual sensing of ultra-high temperature and strain
}

Kevin Cook, Zengling Ran, Yuan Gong, Yunjiang Rao, John Canning

Kevin Cook, Zengling Ran, Yuan Gong, Yunjiang Rao, John Canning, "Combining regenerated gratings and optical fibre Fabry-Pérot cavities for dual sensing of ultra-high temperature and strain," Proc. SPIE 9655, Fifth Asia-Pacific Optical Sensors Conference, 965539 (1 July 2015); doi: $10.1117 / 12.2185272$

Event: Fifth Asia Pacific Optical Sensors Conference, 2015, Jeju, Korea, Republic of 


\title{
Combining regenerated gratings and optical fibre Fabry-Pérot cavities for dual sensing of ultra-high temperature and strain
}

\author{
Kevin Cook $^{1}$, Zengling Ran ${ }^{2}$, Yuan Gong ${ }^{2}$, Yunjiang Rao ${ }^{2}$ and John Canning ${ }^{1}$ \\ ${ }^{1}$ interdisciplinary Photonics Laboratories, School of Chemistry, The University of Sydney, NSW 2006, \\ Australia \\ ${ }^{2}$ Key Lab of Optical Fiber Sensing and Communication (Ministry of Education), University of Electronic \\ Science and Technology of China, Chengdu, China
}

\begin{abstract}
The successful regeneration of fibre Bragg gratings (FBGs) inscribed in an inline fibre etalon is demonstrated. The etalon is formed by UV-micromaching of the fibre end-face to form a cylindrical hole, the fibre is then fusion spliced to seal the cavity. Such a fibre device has excellent potential for the simultaneous measurement of ultra-high temperatures and strain.

Keywords: Fiber grating, Fabry-Perot, regenerated gratings, temperature sensing, strain sensing.
\end{abstract}

\section{INTRODUCTION}

In the past few years, the field of regenerated fibre Bragg gratings (FBGs) has been the subject of intense research activity as this member of the FBG family continues to prove itself as a versatile choice when ultrahigh temperature performance is required [1-4]. The remarkable stability at extreme temperatures means that regenerated gratings are now finding applications in a wide variety of sensing applications such as diesel locomotive engine temperature regulation [5], assessment of fire damage to concrete building structures [6] and dual pressure/temperature sensing of gas turbines [7]. To this end, the dual functionality of FBG sensors is a highly desirable quality and can greatly extend prospective application areas. In the work of [5], the regenerated FBG is fabricated in a birefringent fibre that has 2 air holes in the cladding; temperature monitoring is achieved by the traditional wavelength tracking of the FBG reflection and, simultaneously, pressure monitoring is achieved by monitoring the polarisation splitting caused by increased birefringence. In the following paper, we make the first steps towards developing a dual strain/temperature FBG sensors that can operate in ultra-high temperatures. This approach utilises a laser-inscribed air etalon in the core of the standard optical fibre. Previous work has shown that such a fibre etalon exhibits excellent Fabry-Pérot fringes, the proper monitoring of which can allow the accurate measurement of static, quasi-static and dynamic strain [8]. A regenerated FBG is successfully inscribed directly on top of the etalon, giving it the potential for dual strain-temperature sensing at extreme temperatures.

\section{EXPERIMENTS}

In order to form the fibre etalon, a Fluorine $\left(\mathrm{F}_{2}\right)$ laser with wavelength of $157 \mathrm{~nm}$ is used to ablate the core region of the end-face of a cleaved section of standard SMF-28 optical fibre. Both the core and part of the outer cladding is removed to form a cylindrical hole with a depth of $d \sim 30 \mu \mathrm{m}$ and a diameter of approximately $d=50 \mu \mathrm{m}$ centered on the core axis of the fibre. Figs. 1(a) - (c) show a schematic of the etalon fabrication procedure. Fig. 1(d) shows various images of the etalon obtain using a scanning electron microscope (the first image is the fibre end-face after laser machining). A fluence of $f=12 \mathrm{~J} / \mathrm{cm}^{2}$ and a repetition rate $\mathrm{RR}=20 \mathrm{~Hz}$ were used and an exposure time of only $\tau=8 \mathrm{~s}$. After this micromachining process, the fibre is simply fusion spliced to another length of cleaved fibre to form an air cavity in-line with the fibre core. The spontaneous emission from an Erbium-doped fibre amplifier (EDFA) is used to measure the reflection spectra in the region of $\sim(1510-1590) \mathrm{nm}$. The reflection spectra exhibited the characteristics of a FabryPérot etalon, with strong fringes with a contrast of around $10 \mathrm{~dB}$ observed.

* john.canning@sydney.edu.au; phone 6129351 1934; fax 61293513329

Fifth Asia-Pacific Optical Sensors Conference, edited by Byoungho Lee, Sang-Bae Lee,

Yunjiang Rao, Proc. of SPIE Vol. 9655, 965539 - (c) 2015 SPIE

CCC code: $0277-786 X / 15 / \$ 18 \cdot$ doi: $10.1117 / 12.2185272$

Proc. of SPIE Vol. $9655965539-1$ 


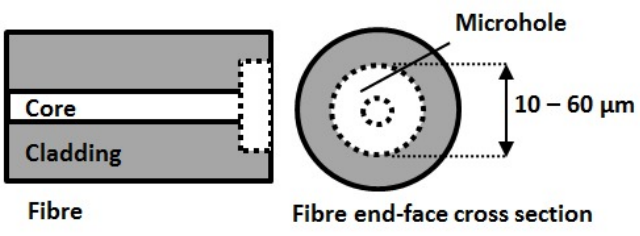

(a)

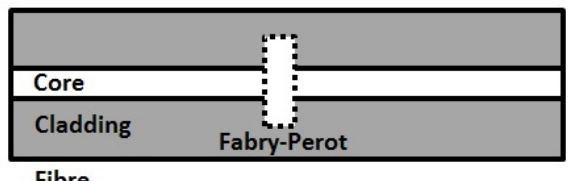

(c)
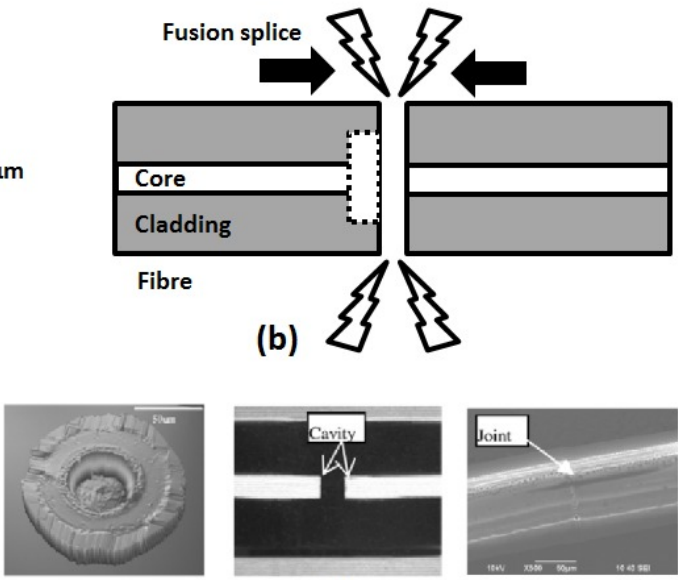

(d)

Figure 1. (a) Depiction of laser-machined end-face; (b) Fusion splicing to form an in-line air cavity; (c) Final fibre etalon; (d) SEM images of laser-machined end face and the side view after splicing.

Prior to grating writing, etalons are hydrogen-loaded in order to assist inscription of the seed grating and also the regeneration process. Etalon-containing fibre samples were pressurized at $18 \mathrm{MPa}$ and kept at $T=80^{\circ} \mathrm{C}$ for 48 hours before unloading. The output of a $193 \mathrm{~nm} \operatorname{ArF}$ laser $\left(f=90 \mathrm{~mJ} / \mathrm{cm}^{2}\right.$; RR $\left.=30 \mathrm{~Hz}\right)$ is used to inscribe seed FBGs using direct writing through a phase mask. The central wavelength of the FBG was $\lambda_{\text {Bragg }}=1548 \mathrm{~nm}$ and the strengths were $R$ $>50 \mathrm{~dB}$ when measured in transmission. The grating was written directly over the etalon region with the etalon located at the centre of the grating. Fig. 2(a) shows the initial seed grating reflection spectra. Directly after grating inscription, the grating was subjected to the required thermal treatment for regeneration. The grating was placed into a computercontrolled oven and the temperature was increased to $950{ }^{\circ} \mathrm{C}$ over a period of 60 mins. When the $950{ }^{\circ} \mathrm{C}$ was reached, the temperature was fixed for 20 mins for regeneration to occur before being cooled down to room temperature over 2 hours. The regenerated grating strength was $R \sim 30 \%$ in reflection after cool-down and is also shown in Fig. 2(a). After regeneration, the etalon fringes were found to be still clearly visible with only a slight reduction in fringe contrast to $8 \mathrm{~dB}$ as shown in Fig. 2(b).
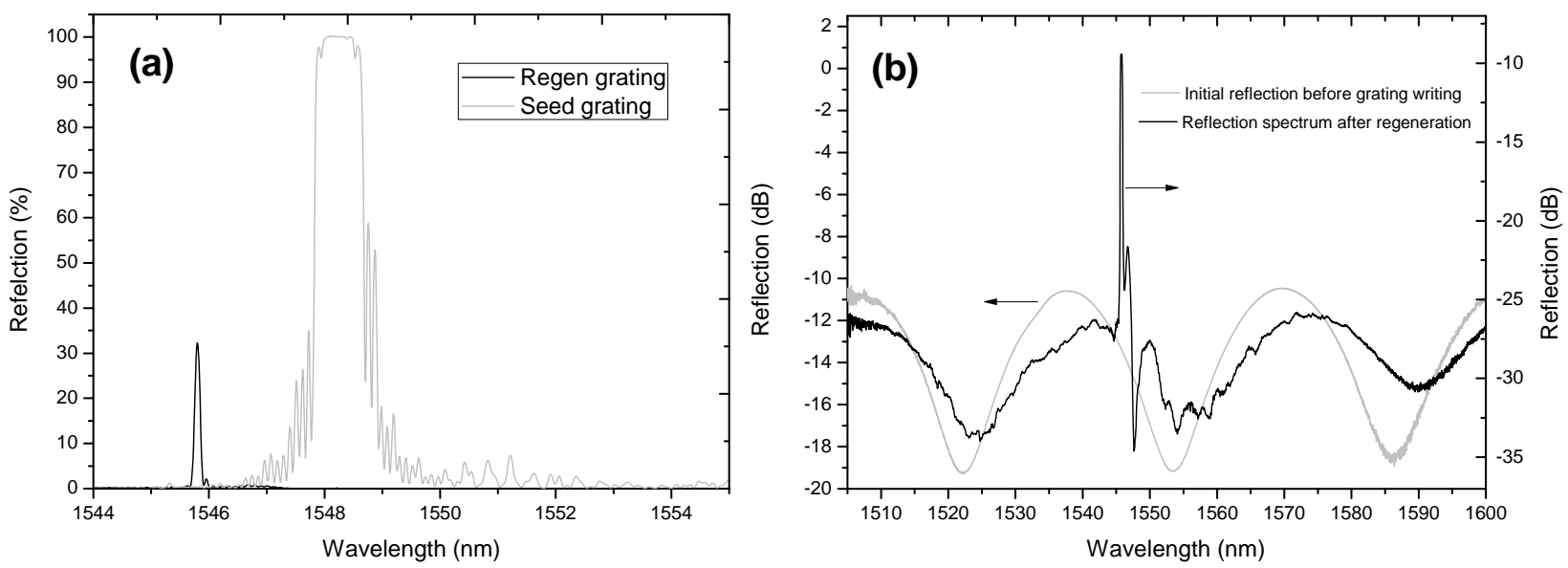

Figure 2. (a) Reflection spectra of seed and regenerated gratings; (b) Initial (prior to grating fabrication) and final (post regeneration) reflection spectra showing Fabry-Pérot fringes. 


\section{CONCLUSIONS}

We have successfully-demonstrated the fabrication of a regenerated grating directly superimposed onto a section of fibre containing a laser-machined air cavity. Such a fibre device has excellent potential as a dual temperature and (static/dynamic) strain sensor owing to the low thermal cross-sensitivity of the etalons which makes it possible to discriminate between changes caused by temperature and strain. For strain sensing, the regenerated FBG monitors $\mathrm{T}$, the contribution of which can be extracted from the etalon measurements to obtain strain. Application areas include sensing in harsh industrial environments such as gas turbines and engines.

\section{ACKNOWLEDGEMENTS}

The authors acknowledge the support from the Australian Research Council (ARC), Grant numbers: FT110100116 \& DP140100975.

\section{REFERENCES}

[1] S. Bandyopadhyay, J. Canning, M. Stevenson, K. Cook, "Ultra-high temperature regenerated gratings in boron codoped germanosilicate optical fibre using 193nm”, Opt. Lett., 33, 1917-1919, (2008).

[2] J. Canning, S. Bandyopadhyay, P. Biswas, M. Aslund, M. Stevenson, K. Cook, "Regenerated fibre Bragg gratings", in Frontiers in Guided Wave Optics and Optoelectronics, (Ed. Bishnu Pal), IN-TECH, Vienna, Austria, European Union, (2010) and refs therein.

[3] S. Bandyopadhyay, J. Canning, P. Biswas, M. Stevenson, K. Dasgupta, "A study of regenerated gratings produced in germanosilicate fibres by high temperature annealing”, Opt. Express, 19 (2), 1198-1206, (2011).

[4] J. Canning, S. Bandyopadhyay, M. Stevenson, P. Biswas, J. Fenton, M. Aslund, "Regenerated Gratings", J. Euro. Opt. Soc. Rapid Publications, 4, 09052, (2009).

[5] F. Mezzadri, F.C. Janzen, C. Martelli, J. Canning, K. Cook, "Monitoramento de temperatura em turbina de motor diesel de locomotiva com sensor a fibra óptica”, MOMAG2012 - 15th Brazilian Symposium for Microwaves and Optoelectronics (SBMO) and the 10th Brazilian Congress for Electromagnetics (CBMag), Brazil (2012) .

[6] P. Rinaudoa, B. Torresa, I. Paya-Zafortezaa, P. A. Calderóna and S. Salesb, “ Evaluation of new regenerated fiber Bragg grating hightemperature sensors in an ISO 834 fire test,” Fire Safety Journal, 71, 332-339, (2014).

[7] T. Chen, R. Chen, C. Jewart, B. Zhang, K. Cook, J. Canning and K. Chen, "Regenerated gratings in air-hole microstructured fibers for hightemperature pressure sensing,” Opt. Lett., 36 (18), 3542-3544, (2011).

[8] Z. L. Ran, Y. J. Rao, X. Liao, and H. Y. Deng, "Self-Enclosed All-Fiber In-Line Etalon Strain Sensor Micromachined by 157-nm Laser Pulses,” Journal of Lightwave Technology, 27, 3143-3149, (2009). 